\title{
Behavioural and Psychological Problems in Dementia
}

\section{Swaleha Mujawar ${ }^{1}$, Miliind Sose ${ }^{2}$, Chetan Dewan ${ }^{2}$, Suprakash Chaudhury $^{1 *}$ and Daniel Saldanha ${ }^{1}$}

${ }^{1}$ Department of Psychiatry, Dr D Y Patil Medical College, Hospital and Research

Centre, Dr D Y Patil University, Pune, India

${ }^{2}$ Karve Institute of Social Service, Pune, India

*Corresponding Author: Suprakash Chaudhury, Department of Psychiatry, Dr D Y

Patil Medical College, Hospital and Research Centre, Dr D Y Patil University, Pune, India.
Received: September 30, 2020

Published: October 12, 2020

(C) All rights are reserved by Suprakash

Chaudhury., et al.

\begin{abstract}
Behavioural disturbances in the form of agitation and aggression occur frequently in persons with dementia. Mean prevalence of behavioural disturbances in dementia is reported to be as high as $46.2 \%$. Various psychological and behavioural symptoms reported in dementia apart from agitation and aggression include apathy, delusions, hallucinations, irritability, eating disturbances and sleep disorders. Other symptoms seen include hyperactivity, affective symptoms including depression and anxiety. The neurobiological changes seen in dementia include decrease in cholinergic and serotonergic activity, alterations in the noradrenergic systems; decrease in the norepinephrine level and an increase in the level of its major metabolite 3-methoxy-4-hydroxyphcnylglycol. Tools used for assessing include the behavioral pathology in Alzheimer's disease rating scale (BFHAVE-AD), the Cohen-Mansfield Agitation Inventory (CMAI), the neuropsychiatric inventory (NPI) and the behavioral rating scale for dementia (BRSD). A variety of treatments are available to alleviate the behavioural symptoms. Antipsychotics have been found to be the treatment of choice for behavioural disturbances. Treatment of depression in dementia comprises pharmacotherapy and nonpharmacological strategies, such as psychological interventions to enhance quality of life. Psychological intervention begins with the development of a daily routine and the organization of activities which the patient enjoys. A detailed treatment regime is discussed in the article below.

Keywords: Alzheimer's Disease; Cognitive Deficits; Psychological Symptoms; Apathy; Aggression; Delusions; Psychosis; Hallucinations; Irritability; Sleep Disorders
\end{abstract}

\section{Introduction}

Dementia is characterised by the deterioration of mental functioning. It includes the various cognitive and intellectual deficits, which affects the ability to carry out everyday tasks by the individual [1]. Behavioural disturbances in the form of agitation and aggression occur frequently in persons with dementia. Mean prevalence of behavioural disturbances in dementia is reported to be as high as $46.2 \%$ [2]. Alzheimer's disease (AD) which is the most common cause of dementia affects almost 15 million people worldwide [3]. Subjects with Down's syndrome are at risk of early onset dementia of the Alzheimer type [4]. Almost one in three people with Down's syndrome will develop dementia in their 50s, as well as over half of those who live to the age of 60 or over as shown by research [5]. Depression and dementia were associated in people who have Down's syndrome [6]. Also, the prevalence of dementia is greater in people with learning disabilities as opposed to the general population [7].

The behavioural and psychological or neuropsychiatric symptoms of dementia are noncognitive symptoms that constitute a major component of dementia irrespective of the subtype [8]. The neuropsychiatric symptoms of dementia are diverse, capricious, and may alter the mood, content of thought, perception, and motor function. Commonly seen behavioural and psychological symptoms in dementia include agitation, irritability, aggression, apathy, delusions, hallucinations, eating disturbances and sleep disorders. 
Other symptoms seen include hyperactivity, affective symptoms including depression and anxiety [9]. Personality changes are most common in $\mathrm{AD}$ and affect approximately $70 \%$ of patients [10]. Approximately $80 \%$ of Alzheimer's disease patients are apathetic during the progression of their illness [11]. Personality changes including disinterest in environment or inappropriate social behaviour may be seen in $\mathrm{AD}$ [10]. Behavioural disturbances like verbal or physical aggression, urinary incontinence, and excessive wandering, are a major source of caregiver burden and an important contributor to the decision to admit $\mathrm{AD}$ patients to institutionalized long-term care [12]. Another type of dementia is Frontotemporal dementia (FTD), a syndrome first by Pick, is characterized by disturbing behaviour [13]. Early loss of personal and social awareness, early decline in social interpersonal conduct, early loss of insight, and emotional blunting are characteristic features of this dementia type. The progression of $\mathrm{AD}$ may be worsened by a few factors like personality traits, unfamiliar surroundings etc [14]. A supportive atmosphere may have a positive impact on the patient's physical and psychological well-being just as a deficient social support has a negative impact [15].

The neurobiological changes seen in dementia include decrease in cholinergic and serotonergic activity, alterations in the noradrenergic systems; decrease in the norepinephrine level and an increase in the level of its major metabolite 3-methoxy-4-hydroxyphcnylglycol [16]. The extent of these deficits depends on the progression of the neurodegeneration and the functional integrity of other neurotransmitter systems [14]. In case of psychotic symptoms changes in brain metabolism in the mesotemporal and frontal brain areas are seen [17].

\section{Assessment}

Although more than 100 rating scales for the assessment of BPSD exist, neither the International Statistical Classification of Diseases, $11^{\text {th }}$ Revision (ICD-11) nor the Diagnostic and Statistical Manual of Mental Disorders, Fifth Edition (DSM-5) provide detailed definitions of behavioral disturbances in dementia [18]. Tools used for assessing include the Behavioral Pathology in Alzheimer's Disease Rating Scale (BFHAVE-AD) [19] the Cohen-Mansfield Agitation Inventory (CMAI) $[20,21]$ the Neuropsychiatric Inventory (NPI) [22] and the Behavioral Rating Scale for Dementia (BRSD) [23]. BEHAVE-AD assess behavioural and psychological elements of Alzheimer disease, however the scale may not be generalizable as it focuses specifically on the symptoms associated with AD. Some other scales which can be used to assess AD include the Present
Psychiatric State Learning disability Scale (PPSD) and Psychiatric Assessment Schedule for Adults with Developmental Disabilities (PAS-ADD). The vast number of studies of have used the Neuropsychiatric Inventory (NPI) which was developed by Cummings., et al [14]. There are several versions of the NPI, such as the NPI-Q NPI-NH and the NPI-C.

\section{Management}

There is no known cure for progressive dementias, however a variety of treatments are available to alleviate the associated symptoms [24]. Antipsychotics have been found to be the treatment of choice for behavioral disturbances [25]. However, even at low doses of haloperidol ( 2 to $3 \mathrm{mg}$ /day), $20 \%$ of AD patients with psychosis and disruptive behaviors developed moderate to severe extrapyramidal side effects [26]. Hence, lower starting doses are recommended. Treatment of depression in dementia comprises pharmacotherapy and nonpharmacological strategies, such as psychological interventions to enhance quality of life (e.g. emotion-oriented psychotherapy and stimulation oriented treatment, including art. or social therapies, exercise and dance) [27]. Developing a daily routine and the institution of pleasant activities are considered first step [28]. The new generation of antidepressants, particularly the SSRIs, the reverse inhibitors of monoamine oxidase A (RIMAs), tianeptine, venlafaxine, and mirtazapine have been demonstrated to be as efficient, as traditional TCAs with a better tolerability [29]. In patients who suffer from insomnia the treatment consists of mainly pharmacological agents like chloralhydrate which can be given at doses of $250 \mathrm{mg}$ to $1000 \mathrm{mg}$ in a day. Other medications include 5 to $10 \mathrm{mg}$ of Zolpidem (at night), 3.75 - $7.5 \mathrm{mg}$ of Zopiclone. A cyclopyrrolone-derivative and low-potency neuroleptics (e.g. melperone $25-75 \mathrm{mg}$ at night) have been found effective [30].

\section{Conclusion}

Dementia especially $\mathrm{AD}$ is fairly common and the number of people with $\mathrm{AD}$ in increasing at a fast pace. It leads to many behavioural and psychological problems like depression, psychosis which lead to functional impairment and disruption of daily life. Early identification and timely treatment will help in stopping progression of the disease and will lead to a better quality of life.

\section{Bibliography}

1. Gustafson L. "What is dementia?" Acta Neurologica Scandinavica 168 (1996): 22-24. 
2. Purandare N., et al. "Behavioural and psychological symptoms of dementia". Journal of Clinical Gerontology and Geriatrics 3 (2000): 245-260.

3. Honig LS and Mayeux R. "Natural history of Alzheimer's disease”. Aging 13.3 (2001): 171-182.

4. Bush A and Beail N. "Risk factors for dementia in people with down syndrome: issues in assessment and diagnosis". American Journal of Mental Retardation 109.2 (2004): 83-97.

5. Watchman K. "Learning Disabilities and Dementia” (2008).

6. Burt DB., et al. "Depression and the onset of dementia in adults with mental retardation". American Journal of Mental Retardation 96.5 (1992): 502-511.

7. Cooper SA. "High prevalence of dementia among people with learning disabilities not attributable to Down's syndrome”. Psychological Medicine 27.3 (1997): 609-616.

8. McKeith I and Cummings J. "Behavioural changes and psychological symptoms in dementia disorders". The Lancet Neurology 4.11 (2005): 735-742.

9. Van der Linde RM., et al. "Grouping of behavioural and psychological symptoms of dementia". International Journal of Geriatric Psychiatry 29.6 (2014): 562-568.

10. Eastwood R and Reisberg B. "Mood and behaviours". In: Gauthier S, ed. Clinical Diagnosis and Management of Alzheimer's Disease". London, UK: Martin Dunitz (1996): 175-190.

11. Ravona-Springer R and Davidson M. "Depression and apathy in dementia". Romanian Journal of Psychopharmacology 49 (2009): 183-190.

12. Deutsch LH., et al. "Psychosis and physical aggression in probable Alzheimer's disease". The American Journal of Psychiatry 148.9 (1991): 1159-1163.

13. Mychack P., et al. "The influence of right frontotemporal dysfunction on social behavior in frontotemporal dementia". Neurology 56.11-4 (2001): S11-S15.

14. Müller-Spahn F and Hock C. "Behavioral disturbances in old age”. In: Lader M, Naber D, eds. Difficult Clinical Problems in Psychiatry. London, UK: Martin Dunitz (1999): 181-198.

15. Sandman PO. "Influence of the patient's environment on the progression of Alzheimer's disease". Neurobiology of Aging 16.6 (1995): 871-882.
16. Raskind MA and Peskind ER. "Neurobiologic bases of noncognitive behavioral problems in Alzheimer disease". Alzheimer Disease and Associated Disorders 8.3 (1994): 54-60.

17. Bondareff W. "Neuropathology of psychotic symptoms in Alzheimer's disease". International Psychogeriatric 8.3 (1996): 233-272.

18. Zaudig M. "Behavioral and psychological symptoms of dementia in the International Classification of Diseases (ICD-10) and beyond (ICD-11)". International Psychogeriatric 12.1 (2000): 29-40.

19. Reisberg B., et al. "Behavioral symptoms in Alzheimer's disease: phenomenology and treatment". The Journal of Clinical Psychiatry 48 (1987): 9-15.

20. Cohen-Mansfield JJ. "Agitated behaviors in the elderly. II. Preliminary results in the cognitively deteriorated". Journal of the American Geriatrics Society 34.10 (1986): 722-727.

21. Cohen-Mansfield J., et al. "A description of agitation in a nursing home". The Journals of Gerontology 44.3 (1989): M77-M84.

22. Cummings JL., et al. "The Neuropsychiatric Inventory: comprehensive assessment of psychopathology in dementia". Neurology 44.12 (1994): 2308-2314.

23. Tariot PN., et al. "The Behavior Rating Scale for Dementia of the Consortium to Establish a Registry for Alzheimer's Disease. The Behavioral Pathology Committee of the Consortium to Establish a Registry for Alzheimer's Disease". The American Journal of Psychiatry 152.9 (1995): 1349-1357.

24. Alzheimers Association, What is Dementia (2015).

25. Cowles C. "Nursing Home Statistical Yearbook". Anacortes, Wash: Cowles Research Group (1997).

26. Devanand DP., et al. "A randomized, placebo-controlled dosecomparison trial of haloperidol for psychosis and disruptive behaviors in Alzheimer's disease". The American Journal of Psychiatry 155.11 (1998): 1512-1520.

27. Small GW., et al. "Diagnosis and treatment of Alzheimer disease and related disorders. Consensus statement of the American Association for Geriatric Psychiatry, the Alzheimer's Association, and the American Geriatrics Society". The Journal of the American Medical Association 278.16 (1997): 1363-1371.

28. Lyketsos CG and Olin J. "Depression in Alzheimer's disease: overview and treatment". Biological Psychiatry 52.3 (2002): 243-252. 
29. Montgomery SA and Kasper S. "Comparison of compliance between serotonin reuptake inhibitors and tricyclic antidepressants: a meta-analysis". International Clinical Psychopharmacology 9.4 (1995): 33-40.

30. Rabins PV. "Behavioral disturbances of dementia: practical and conceptual issues". International Psychogeriatric 8.3 (1996): 281-291.

\section{Assets from publication with us}

- Prompt Acknowledgement after receiving the article

- Thorough Double blinded peer review

- Rapid Publication

- Issue of Publication Certificate

- High visibility of your Published work

Website: www.actascientific.com/

Submit Article: www.actascientific.com/submission.php

Email us: editor@actascientific.com

Contact us: +919182824667 